www.jmscr.igmpublication.org

Impact Factor 5.84

Index Copernicus Value: 83.27

ISSN (e)-2347-176x ISSN (p) 2455-0450

crossref DOI: https://dx.doi.org/10.18535/jmscr/v5i1.61

Journal Of Medical Science And Clinical Research

IGM Publication

An Official Publication of IGM Publication

\title{
Effectiveness of Proprioceptive Neuromuscular Facilitation on Spasticity in Hemiplegia: Randomised Controlled Trial
}

Authors

Ujwal Lakshman Yeole $^{{ }^{*}}$, Sakshi Pritam Arora ${ }^{2}$, Gaurai Mangesh Gharote ${ }^{3}$, Rasika Balasaheb Panse ${ }^{4}$, Pournima Ajinkya Pawar ${ }^{5}$, Shweta Anil Kulkarni ${ }^{6}$

${ }^{1}$ MPT, Principal \& Associate Professor, Dept. of Physiotherapy, Tilak Maharashtra Vidyapeeth, Pune

Email:drujwalyeole@gmail.com

${ }^{2}$ Intern, Dept. of Physiotherapy, Tilak Maharashtra Vidyapeeth, Pune-411037

Email: sakshiparora@gmail.com

${ }^{3}$ Assistant Professor, MPT, Dept. of Physiotherapy, Tilak Maharashtra Vidyapeeth, Pune-411037

Email: gaurai.gharote@gmail.com

${ }^{4}$ Assistant Professor, MPT, Dept. of Physiotherapy, Tilak Maharashtra Vidyapeeth, Pune-411037

Email: panserasika09@gmail.com

${ }^{5}$ Assistant Professor, MPT, Dept. of Physiotherapy, Tilak Maharashtra Vidyapeeth, Pune-411037

Email: pawarpournima@gmail.com

${ }^{6}$ Assistant Professor, MPT, Dept. of Physiotherapy, Tilak Maharashtra Vidyapeeth, Pune-411037

Email: coolkarnishweta89@gmail.com

\section{ABSTRACT}

Introduction: Stroke is one of the major causes of morbidity and mortality worldwide. Spasticity is one of the positive feature of stroke. Hence, this study aimed at evaluation of effectiveness of propriocetive neuromuscular facilitation (PNF) over conventional physiotherapy on spasticity in hemiplegia.

Materials and Methods: Randomised controlled trial was done on 30 stroke patients with minimum Grade 1 spasticity. The subjects were randomly allotted for intervention period of 4 weeks into two groups with those receiving PNF technique and conventional physiotherapy. The spasticity and functional independency was evaluated using Ashworth Scale and Barthel index respectively results obtained were compared.

Results: The Ashworth Scale in PNF group showed significant improvement from $2.46 \pm 0.51$ to $1.13 \pm 0.35$ as compared to conventional group with $2.4 \pm 0.5$ to $1.86 \pm 0.35$. The Barthel index in PNF group showed significant improvement from $54.33 \pm 7.52$ to $85 \pm 5$ as compared to conventional group with $53 \pm 2.53$ to $79 \pm 7.6$.

The ROM also had shown significant improvement in PNF group.

Discussion: Both the techniques showed significant reduction in spasticity measured on Ashworth scale, with PNF being more effective ( $p<0.0001)$. The improvement in Barthel Index showed both the interventions to be effective with PNF being more effective in improving the functional independency $(p<0.0001)$. Patients treated with PNF showed significant improvement in shoulder joint abduction, adduction ( $p<0.0001)$; elbow joint flexion, extension $(p=0.0042)$; hip joint external rotation $(p=0.0098)$ and flexion $(p=0.0091)$ and extension ( $p=0.0091$ ) of knee joint as compared to conventional group.

Conclusions: PNF technique is significantly effective over conventional physiotherapy for reducing spasticity and improving functional activities in hemiplegia.

Keywords: Barthel Index, Modified Ashworth Scale, Range of motion, Stroke. 


\section{INTRODUCTION}

Stroke, described as the sudden development of a neurologic deficit caused by abnormalities of blood supply ${ }^{(1)}$ is one of the major causes of morbidity and mortality worldwide ${ }^{(2)}$. Damage to the pyramidal tract and its accompanying parapyramidal (corticoreticulospinal) fibers gives rise to the upper motor neuron syndrome (3), including positive and negative features. Positive features include spasticity and abnormal postures and negative features include those that have been lost such as strength and dexterity ${ }^{(4)}$.

Spasticity is abnormal muscle tone recognised clinically as resistance to passive muscle stretch which increases with velocity of stretch ${ }^{(5)}$. It is more formally defined as: 'a motor disorder characterised by velocity dependent increase in tonic stretch reflexes with exaggerated tendon jerks, resulting from hyperexcitability of the stretch reflex' ${ }^{(6)}$.

Stroke affecting the motor cortex or internal capsule commonly produces initial hypotonia and absent tendon jerks, followed several weeks later by spastic hypertonia in the antigravity muscles ${ }^{(5)}$. The upper limb adopts an adducted posture at the shoulder and a flexed posture at the elbow and wrist, with the fingers flexed into the palm. In the lower limb there is hip and knee extension, with plantarflexion at the ankle ${ }^{(5)}$.

Because of spasticity the affected muscles and tendons become tight and stiff which causes problems in performing daily activities, like walking, standing and performing daily chores. Generally symptoms include exaggerated muscle tone, uncontrollable movement such as rapid muscle contractions and leg-crossing, fixed joints, exaggerated tendon reflexes and shortened tendons ${ }^{(5)}$.

There are various schools of thoughts and treatment protocols are available for reducing spasticity which includes passive and active movement-based approaches. Passive movementbased approaches include combination of neural facilitation techniques, rhythmic passive movements and proprioceptive neuromuscular facilitation. Active movement-based approaches include active exercise interventions such as hydrotherapy and walking ${ }^{(5)}$.

PNF techniques rely mainly on stimulation of the proprioceptors for increasing the demand made on the neuromuscular mechanism to obtain and facilitate its response. It uses proprioceptive, cutaneous, auditory input to produce functional improvement in motor output and in the rehabilitation of many injuries ${ }^{(7)}$. The techniques of PNF are composed of both rotational and diagonal exercise patterns. The exercise pattern is initiated with the muscle groups in the lengthened or stretched position, the muscle group is then contracted, moving the body part though the range of motion to a shortened position. Putting the muscles needed to be stimulated in a stretched position $^{(7)}$.

The present study was done to evaluate spasticity, functional activities in hemiplegic and to study the effectiveness of PNF over conventional physiotherapy for reducing spasticity and improving functional activities in hemiplegia.

\section{METHODS}

Randomised controlled trial was done on 30 stroke patients with minimum Grade 1 spasticity on Ashworth Scale. The subjects were randomly allotted for intervention period of 4 weeks into two groups with those receiving PNF technique (Group $\mathrm{A}=15$, mean age 58.06 \pm 8.79 ) and conventional physiotherapy (Group $\mathrm{B}=15$, mean age 59.73 \pm 9.52 ). Spasticity and functional independency was evaluated using Ashworth Scale and Barthel index respectively on day1, at the end of second week and fourth week and the results obtained were compared.

PNF Technique: The intervention of Group A included patterns of facilitation i.e.D1 and D2 flexion extension for both upper limb and lower limb with stretch stimulus and stretch reflex. The D1 flexion for upper limb included flexionabduction with lateral rotation and D1 extension included extension-adduction with medial rotation. The D2 flexion included flexion- 
adduction with lateral rotation and D2 extension included extension-abduction with medial rotation. Similarly, for lower limb, D1 flexion included flexion-abduction with medial rotation and D1 extension included extension-adduction with lateral rotation. The D2 flexion included flexion-adduction with lateral rotation and D2 extension included extension-abduction with medial rotation. The duration of treatment session was 30 to 40 minutes including the rest period and was done thrice a week for 4 weeks.

Conventional Physiotherapy: The intervention of Group B included stretching with three repetitions each, strengthening with weight cuffs with 10 seconds hold and 10 repetitions each, wobble board exercises were given for 2-3 minutes progressing by forward stepping, backward stepping on wobble board along with weight shifting, Gait training at parallel bar. The duration of treatment session was 40 to 50 minutes including the rest period and was done thrice a week for 4 weeks.
The post-treatment results were noted and compared with the pre-treatment findings for spasticity using Ashworth scale, Barthel index and range of motion. The statistical analysis was done using ANOVA test and unpaired t-test.

\section{RESULTS}

Table 1 demonstrates improvement in spasticity on Ashworth scale of patients treated with PNF was extremely significant $(\mathrm{p}<0.0001)$ as compared to those treated with conventional physiotherapy. Also patient's participation in activities of daily living measured on Barthel index showed extremely significant improvement in PNF group $(\mathrm{p}<0.0001)$ as well as conventional physiotherapy $(\mathrm{p}<0.0001)$.

Table 2 demonstrates that patients treated with PNF showed significant improvement in shoulder joint abduction, adduction ( $\mathrm{p}<0.0001)$; elbow joint flexion, extension $(\mathrm{p}=0.0042)$; hip joint external rotation $(\mathrm{p}=0.0098)$ and flexion $(\mathrm{p}=0.0091)$ and extension $(\mathrm{p}=0.0091)$ of knee joint as compared to conventional group.

Table 1 demonstrates improvement in spasticity on Ashworth Scale and functional activities on Barthel Index

\begin{tabular}{|l|l|l|l|l|l|l|}
\hline & \multicolumn{3}{|l|}{ Ashworth Scale } & \multicolumn{2}{l|}{ Barthel Index } & \\
\hline & PNF & $\begin{array}{l}\text { Conventional } \\
\text { Physiotherapy }\end{array}$ & p value & PNF & $\begin{array}{l}\text { Conventional } \\
\text { Physiotherapy }\end{array}$ & p value \\
\hline 1st day & $2.46 \pm 0.51$ & $2.4 \pm 0.5$ & 0.724 & $54.33 \pm 7.52$ & $53 \pm 2.53$ & 0.5209 \\
end of 2nd week & $2.26 \pm 0.45$ & $2.4 \pm 0.5$ & 0.456 & $64.66 \pm 15.29$ & $53 \pm 2.53$ & 0.0069 \\
\hline end of 4th week & $1.13 \pm 0.35$ & $1.86 \pm 0.35$ & $<0.0001$ & $85 \pm 5$ & $79 \pm 7.6$ & 0.0164 \\
\hline p value & $<0.0001$ & 0.003 & & $<0.0001$ & $<0.0001$ & \\
\hline
\end{tabular}

Table 2 demonstrates improvement in range of motion.

\begin{tabular}{|c|c|c|c|c|c|c|c|}
\hline \multirow{3}{*}{\multicolumn{2}{|c|}{ Joint Movement }} & \multicolumn{3}{|l|}{ Pre } & \multicolumn{3}{|l|}{ Post } \\
\hline & & $\begin{array}{l}\text { Conventional } \\
\text { physiotherapy }\end{array}$ & PNF & \multirow{2}{*}{ p value } & $\begin{array}{l}\text { Conventional } \\
\text { physiotherapy }\end{array}$ & PNF & \multirow{2}{*}{$\begin{array}{l}\mathbf{p} \\
\text { value }\end{array}$} \\
\hline & & \multicolumn{2}{|l|}{ Mean \pm SD } & & \multicolumn{2}{|l|}{ Mean \pm SD } & \\
\hline \multicolumn{2}{|c|}{ Shoulder Flexion } & $101.33 \pm 18.07$ & $106.33 \pm 24.10$ & 0.4986 & $124.66 \pm 17.16$ & \multirow{2}{*}{$\begin{array}{l}144.00 \pm 1 / .5 / \\
47.33 \pm 12.65\end{array}$} & 0.0038 \\
\hline \multicolumn{2}{|c|}{ Extension } & $22.66 \pm 7.52$ & $25.33 \pm 9.53$ & 0.4025 & $37.66 \pm 12.79$ & & 0.0468 \\
\hline & Abduction & $104.66 \pm 9.15$ & $108 \pm 18.20$ & 0.5315 & $130.66 \pm 8.83$ & $149.33 \pm 13.74$ & 0.0001 \\
\hline & Adduction & $104.66 \pm 9.15$ & $108 \pm 18.20$ & 0.5315 & $130.66 \pm 8.83$ & $149.33 \pm 13.74$ & 0.0001 \\
\hline & External Rotation & $48 \pm 13.20$ & $43.66 \pm 12.60$ & 0.3657 & $65.66 \pm 10.15$ & $69.66 \pm 10.25$ & 0.2923 \\
\hline & Internal Rotation & $41 \pm 7.60$ & $37.33 \pm 10.15$ & 0.2725 & $58.33 \pm 7.23$ & $64.66 \pm 10.08$ & 0.058 \\
\hline \multirow[t]{2}{*}{ Elbow } & Flexion & $107.33 \pm 7.98$ & $105.33 \pm 12.45$ & 0.6048 & $128.33 \pm 5.23$ & \multirow{2}{*}{$\begin{array}{l}135.33 \pm 6.93 \\
135.33 \pm 6.93\end{array}$} & 0.0042 \\
\hline & Extension & $107.33 \pm 7.98$ & $105.33 \pm 12.45$ & 0.6048 & $128.33 \pm 5.23$ & & 0.0042 \\
\hline
\end{tabular}


JMSCR Vol||05||Issue||01||Page 15567-15572||January

\begin{tabular}{|ll|lll|lll|}
\hline Wrist & Flexion & $48 \pm 9.22$ & $49.33 \pm 13.61$ & 0.7558 & $63.33 \pm 6.17$ & $72.33 \pm 11.78$ & 0.014 \\
& Extension & $44.66 \pm 10.60$ & $39.33 \pm 9.61$ & 0.16 & $58.66 \pm 9.15$ & $64.66 \pm 4.41$ & 0.03 \\
& Ulnar Deviation & $11.33 \pm 3.51$ & $9.66 \pm 3.99$ & 0.2354 & $24.66 \pm 5.81$ & $26.66 \pm 6.17$ & 0.3688 \\
& Radial Deviation & $9 \pm 2.07$ & $8 \pm 2.58$ & 0.2467 & $19.66 \pm 4.80$ & $24.33 \pm 6.77$ & 0.0382 \\
\hline Hip & Flexion & $78.66 \pm 13.02$ & $62.66 \pm 18.21$ & 0.0099 & $96.33 \pm 11.56$ & $94 \pm 20.19$ & 0.7007 \\
& Extension & $13.33 \pm 6.98$ & $9.66 \pm 6.11$ & 0.1373 & $25.33 \pm 9.15$ & $28.66 \pm 3.51$ & 0.1987 \\
& Abduction & $29.66 \pm 5.49$ & $23.66 \pm 6.39$ & 0.0102 & $40.33 \pm 4.806$ & $43.66 \pm 2.28$ & 0.022 \\
& Adduction & $14.33 \pm 4.57$ & $11.66 \pm 5.23$ & 0.1486 & $24 \pm 5.07$ & $28.33 \pm 9.57$ & 0.1326 \\
& External Rotation & $28.66 \pm 4.80$ & $24 \pm 6.32$ & 0.0307 & $41 \pm 4.30$ & $44.33 \pm 1.75$ & 0.0098 \\
& Internal Rotation & $24 \pm 5.07$ & $22 \pm 7.51$ & 0.4 & $35.66 \pm 5.93$ & $41 \pm 6.08$ & 0.0213 \\
\hline Knee & Flexion & $100.66 \pm 5.93$ & $98 \pm 6.76$ & 0.2607 & $117.33 \pm 9.42$ & $126.66 \pm 8.79$ & 0.0091 \\
& Extension & $100.66 \pm 5.93$ & $98 \pm 6.76$ & 0.2607 & $117.33 \pm 9.42$ & $126.66 \pm 8.79$ & 0.0091 \\
\hline \multirow{2}{*}{ Ankle } & Dorsiflexion & $9 \pm 2.07$ & $7 \pm 2.53$ & 0.0251 & $18.33 \pm 2.44$ & $20 \pm 0.25$ & 0.0175 \\
& Plantarflexion & $29.33 \pm 7.76$ & $24 \pm 7.36$ & 0.0638 & $41.33 \pm 5.81$ & $46.66 \pm 4.88$ & 0.0111 \\
& Inversion & $14 \pm 3.87$ & $13 \pm 6.76$ & 0.623 & $28 \pm 4.55$ & $33 \pm 4.55$ & 0.0055 \\
& Eversion & $8.33 \pm 2.44$ & $6.66 \pm 2.44$ & 0.0719 & $13.33 \pm 2.44$ & $14.6 \pm 1.05$ & 0.0756 \\
\hline
\end{tabular}

\section{Ashworth Scale}

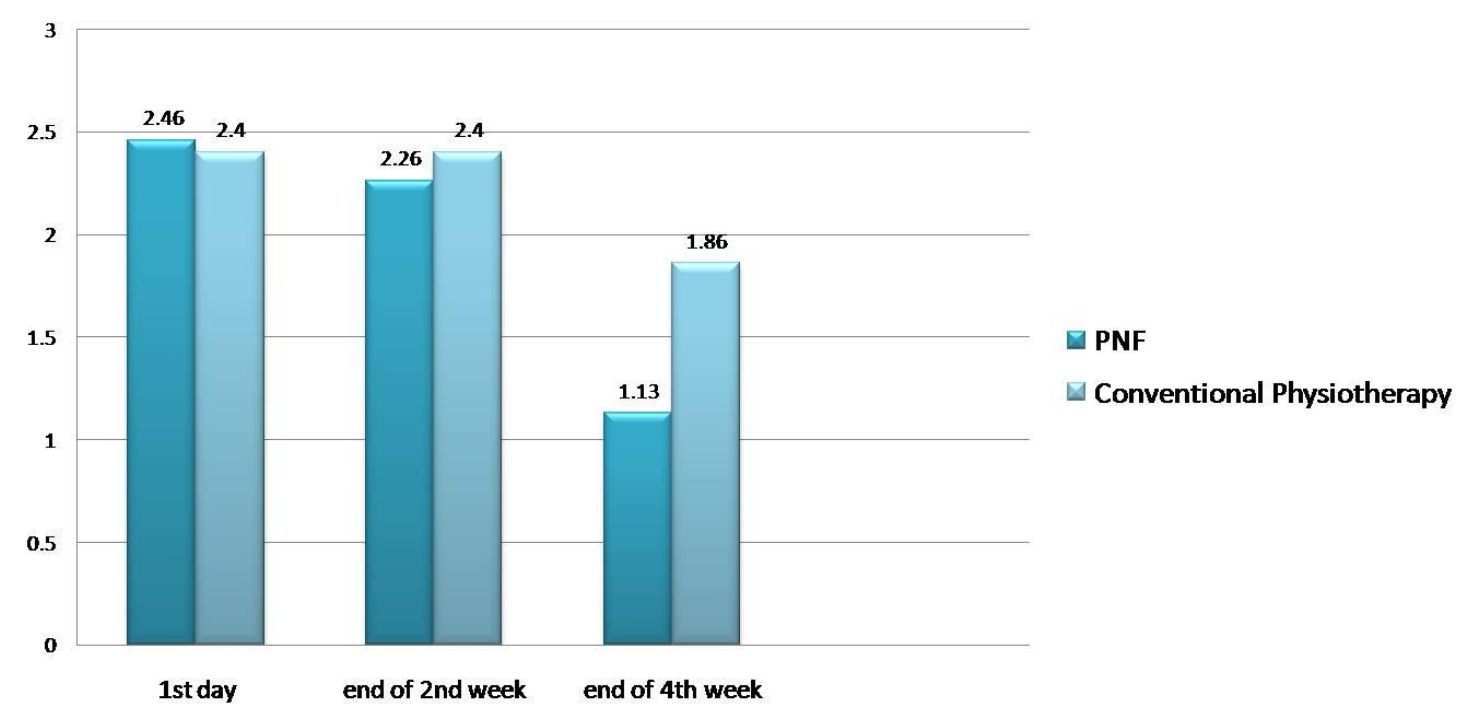

Graph 1: improvement in spasticity on Ashworth Scale

\section{DISCUSSION}

This study was a randomised controlled trial for the evaluation of effectiveness of PNF over conventional physiotherapy in stroke patients. Both the techniques showed significant reduction in the spasticity measured on Ashworth scale, with PNF being more effective than conventional physiotherapy $(\mathrm{p}<0.0001)$. The study done by Kawahira et al. ${ }^{(8)}$ (2004) had demonstrated similar results where rehabilitation programme comprising mainly the PNF technique led to improvement in voluntary movement of the hemiplegics. Improvements of the patients motor function is possible even years after initial lesion when mobilization of the nervous system is included in the treatment program ${ }^{(9)}$. Sullivan PE et al. ${ }^{(10)}$ mentioned PNF to be one of the major therapeutic approaches aimed at improving the important features necessary for the functional activities of hemiplegic patients, such as muscular tone, strength and flexibility.

The improvement in activities of daily living was assessed with Barthel Index showing both the interventions to be effective with PNF being more 
effective in improving the functional independency of stoke patients $(\mathrm{p}<0.0001)$. As per Gardiner ${ }^{(7)}$ PNF contains more of skilled diagonal movements emphasising more on functional activities. The patterns of movements used are spiral and diagonal and they are closely allied to those of normal functional movements of daily living. Wang RY ${ }^{(1)}$ concluded that use of PNF technique results in increased gait speed and cadence. Pil Neo Hwangbo et al. ${ }^{(12)}$ concluded that both traditional rehabilitation therapy and PNF neck pattern exercises are effective in enhancing the ability of chronic stroke patients to control the trunk and to maintain balance.

Patients treated with PNF showed significant improvement in shoulder joint abduction, adduction $(\mathrm{p}<0.0001)$; elbow joint flexion, extension $(\mathrm{p}=0.0042)$; hip joint external rotation $(\mathrm{p}=0.0098)$ and flexion $(\mathrm{p}=0.0091)$ and extension $(\mathrm{p}=0.0091)$ of knee joint as compared to conventional group. PNF stretches the antagonist which leads to stimulation of stretch reflex leading to reciprocal inhibition of agonist resulting in increase in the ROM ${ }^{(7)}$. Proprioceptors situated in the muscle spindles are stimulated by stretching, which increases the intramuscular tension. Stimulation of the muscle spindle elicits a reflex contraction of the muscle provided the stimulus is of threshold value along with intact reflex arc. Bombardment of dormant anterior horn cells by impulses initiated from the spindles increases central excitation and facilitates stimulation of the cells ${ }^{(7)}$ leading to improvement in functional activities and ROM.

\section{CONCLUSION}

PNF technique is significantly effective over conventional physiotherapy for reducing spasticity and improving functional activities in hemiplegia.

\section{LIMITATION}

1. Spasticity being reversible in absence of intervention, this study could not assess whether the effect of interventions were retained after the intervention has stopped.

\section{FUTURE SCOPE OF STUDY}

1. Follow up study can be done without intervention to study the retained effect for short and long term goals.

2. Comparative study of supervise and nonsupervise intervention can be done.

\section{REFERENCES}

1. Caplan IR. Stroke. In Cotran RS, Kumar V and Collins T. (eds.) Robbins Pathologic Basis of Diseases (6th ed). Philadelphia: W.B. Saunders and Company, 1993, pp 1306.

2. Komolafe MA, Ogunlade $\mathrm{O}$ and Komolafe EO. Stroke mortality in a teaching hospital in South Western Nigeria. Afr J of Neuro Sci 2006; 25(2): 75-77

3. Lance JW. The control of muscle tone, reflexes, and movement: Robert Wartenberg lecture. Neurology. 1980;30:13031313.

4. O'Dwyer NJ, Ada L, Neilson PD. Spasticity and muscle contracture following stroke. Brain. 1996;119:1737-1749.

5. Bipin B Bhakta . Management of spasticity in stroke. British Medical Bulletin 2000, 56 (No 2) 476-485.

6. Brown P Pathophysiology of spasticity. Neurol Neurosurg Psychiatry 1994; 57: 773-7.

7. M. Dena Gardiner. The Principles of exercise therapy, fourth edition; Proprioceptive neuromuscular facilitation; chap 9:78-90.

8. Kawahira K, Shimodozono M, Ogata A and Tanaka N. Addition of intensive repetion of facilitation exericse to multidiciplinary rehabilitation promotes motor functional recovery of the hemiplegic lower limb. J Rehab Med 2004. 36(4): 159-164.

9. Patricia M. Davies. Starting Again: Early Rehabilitation afterTraumatic Brain Injury or Other Severe Brain Leison.2003. 
10. Sullivan PE, Markos PD and Minor Md. An Integrated Approach to Therapeutic Exercise: Theory and clinical application. Reston, Va: Reston Ltd., 1982, pp. 199254.

11. Wang RY. Effect of Proprioceptive Neuromuscular Facilitation- the gait of patents with hemiplegia of long and short duration. Physical Therapy. December 1994; 74(12):108-115.

12. Pil Neo Hwangbo, KyouNg DoN Kim. Effects of proprioceptive neuromuscular facilitation neck pattern exercise on the ability to control the trunk and maintain balance in chronic stroke patients. J. Phys. Ther. Sci. 28: 850-853, 2016. 